\title{
EFL LEARNERS' ATTITUDES AND PERCEPTIONS OF ONLINE AND CONVENTIONAL PEER WRITTEN FEEDBACK: A TERTIARY LEVEL EXPERIENCE
}

\author{
Mohammad Hamed Hoomanfard \\ Payame Noor University
}

\begin{abstract}
The present study attempted to uncover EFL learners' perceptions of and attitudes towards peer feedback in writing classes under conventional and computer-mediated conditions. In so doing, the participants who were university upper-intermediate literature sophomores studying in two intact classes were assigned randomly to two control (conventional) and experimental (online) peer feedback treatments. The participants of the two groups took two questionnaires at the beginning and at the end of the treatment. Some of the participants took part in follow-up interviews to disclose their perceptions, attitudes, and experiences of conventional and online peer feedback activity. The results indicated that the participants of both groups were content with their experience of peer feedback activity. They found peer feedback an acceptable activity which provided them with a non-threatening condition to exchange ideas. However, at the end of the treatment, the online group students had more positive perceptions of and attitudes towards peer feedback activity.
\end{abstract}

\section{KEYWORDS: PEER FEEDBACK, PERCEPTIONS, ATTITUDES, CONVENTIONAL FEEDBACK, CMC FEEDBACK}

\section{Introduction}

Peer feedback, endorsed by different theoretical and pedagogical underpinnings, is gaining momentum in the realm of second language writing in the third millennium. Primarily, peer feedback has leaned on Vygotsky's (1978) Zone of Proximal Development, which encourages the existence of social interaction to yield learners' higher levels of ability in their ZPD (Rahimi, 2013). At the heart of these interactions are scaffoldings, which are finely-tuned instructional strategies (Bruner, 1978). In addition to ZPD, collaborative learning theory, bolding the significance of learners' pooling of resources of different kinds (Bruffer, 1984), interaction hypothesis, stressing the benefits of the negotiation of meaning that occurs in the stress-free social interactions between language learners (Jacobs \& McCafferty, 2006), and output hypothesis, which finds learners' production as a vehicle to increase learners' access to better input, force syntactic processing, and develop learners' automaticity, discourse skills and personal voice (Swain, 1985), are mentioned as the theoretical backings of peer feedback (Liu \& Hansen, 2002).

An issue related to peer feedback is the medium through which comments are exchanged. Although peer feedback exchanges were once limited to the conventional media such as oral face-to-face, and conventional written media, computer-mediated communication (CMC), developed in the form of website, weblog, wiki, forum, social network and instant message systems, emerged to be an alternative (Tuzi, 2004; $\mathrm{Wu}, 2006$ ).

In these technologies, computer functions as a tool that mediate the interactions between students and transform the way learners interact with the learning environment (Englert, $\mathrm{Wu}, \& \mathrm{Zhao}, 2005)$. Mediation is the focal concept of Sociocultural Theory (Lantolf \& Poehner, 2008); mediation that can be in the form of psychological tools (e.g., language) or physical tools (e.g., computers, websites, the internet) transforms human actions because the context of interaction is different (Warschauer, 2005).

The present study aims at investigating the effect of employing one of these mediational tools (an interactive website) on second language learners' attitudes towards and perceptions of written peer feedback. Unlike previous studies that were mainly focused on the ultimate outcome of this new mediational tools i.e., learners' writing performance, the present study, by applying a triangulated research design, attempts to uncover the changes that this new tool brings about. Based on the findings of the previous pertinent studies on computer-mediated peer feedback, it is hypothesized that computer-mediated feedback, by its psychological, linguistic, and logistic benefits mentioned in the literature, can lead to a more positive attitudes and perceptions of peer feedback. 


\section{EFL LEARNERS' ATTITUDES AND PERCEPTIONS OF ONLINE AND CONVENTIONAL PEER WRITTEN FEEDBACK: A TERTIARY LEVEL EXPERIENCE}

\section{Literature review}

\section{Computer-Mediated Communication and Computer Mediated Peer Feedback}

Computer-mediated communication is regarded as the newest trend in computer-assisted language learning (CALL) framework. Warschuar and Kern (2000) put this type of communication in the Sociocognitive stage since it provides students with the suitable medium for social interaction. In the Sociocognitive approach to CALL, computers are used as mediational tools that set the conditions for learners to interact with their peers or instructor. Space (place independency), interaction (focus on the written mode rather than other semiotic modes), and time (either synchronous or asynchronous) are three major features of computer-mediated communication mentioned by Breuch (2004). With regard to space, the independency of place depends heavily on whether the communication is established through the internet or a Local Area Network. Although the interactions are usually in the written form, different semiotic systems such as emoticons or spoken messages can be employed to convey the message through new technologies. The best example of synchronous feedback exchange is the use of real time chat services and the best-known asynchronous examples are email services, web pages, cyber bulletin boards, and wikis. Computer-mediate communication has penetrated into different aspects of computer users' lives; one of the areas benefited from CMC is second language classes.

Second language writing programs have benefited from computer-mediated communication for the exchange of comments provided by peers or teachers on learners' texts. The integration of the two types of mediation, i.e. peer feedback and computermediated has given birth to a type of feedback, which is getting popularity as time goes by.

\section{Computer-mediated feedback and learners' attitudes and perceptions}

Learning a second language is not a successive occurrence of the cause (input) and the effect (extension of learners' interlanguage); but there are diverse affective, social, cognitive, and linguistic factors that alter the outcome of this process (Skehan, 1998). One of the mediating variables reported to affect second language learners' performance is learners' perceptions (Strobl, 2015). The study of learners' perceptions and attitudes is one of the main aspects of second language peer feedback research (Ferris, 2003), which has been usually marginal to other issues related to peer feedback.

Although during the last two decades, a number of studies (e.g., Tang \& Tithecott, 1999; Roskams, 1999; Rollinson, 2004; Fujieda, 2007) have investigated second language learners' perceptions and attitudes towards conventional peer feedback, the number of studies on the perceptions in the computer-mediated peer feedback context is sparse.

Some studies (Dippold, 2009; Guardado \& Shi, 2007) examined online students' perceptions and attitudes while some others (DiGiovanni \& Nagaswami, 2001; Ho \& Savignon, 2007; Xu, 2007) compared the perceptions of online and conventional groups to find possible disparate perceptions and attitudes towards peer feedback provided through different media, and Chang (2012) compared online synchronous, online asynchronous, and face to face feedback.

Employing interviews, Guardado and Shi (2007) investigated the perceptions of ESL (English as a Second Language) learners taking a sheltered credit course at a western-Canadian university. Their study revealed student's mixed feelings about online peer feedback practiced by Blackboard online tool. Some of the participants welcomed this new peer feedback exchange system, but some disliked it. A part of this dissatisfaction was found attributable to the lack of interaction in the process of comment exchange. Dippold's (2009) study is another investigation that, employing a questionnaire, investigated the perceptions of those who were learning German as a Second Language. The results of this study indicated the positive attitude towards online peer feedback. The interactive nature of this activity and the playfulness were the two reported advantages.

Some other scholars conducted comparative studies to pinpoint the differences between EFL/ESL learners' attitudes and perceptions. DiGiovanni and Nagaswami (2001), for example, compared ESL pre-university students' perceptions of face-toface peer feedback with online peer feedback. The results of their study revealed that the students were of different perceptions; some preferred the online activity, some voted for the conventional face-to-face activity, and the rest of the participants found both conventional and computerized types beneficial in their own ways. In another attempt to uncover ESL learners' perceptions of conventional and online feedback, Xu (2007) employed a questionnaire to collect data. Word processor was employed for annotating the points and an interactive website was used to exchange the comments. The findings of their study 


\section{EFL LEARNERS' ATTITUDES AND PERCEPTIONS OF ONLINE AND CONVENTIONAL PEER WRITTEN FEEDBACK: A TERTIARY LEVEL EXPERIENCE}

indicated the students' positive attitude towards CMC feedback. He added that the use of new technology motivated students to be on-task all the time and be more motivated to take part in the assigned tasks. In the same year, Ho and Savignon (2007) compared face to face and online written feedback. In this study, word processor and email were used to exchange comments. The results of this study, the data of which was collected by a questionnaire, indicated that the majority of the students found a combination of CMC and face-to-face feedback as the best possible type of feedback. The absence of interaction in the CMC feedback was mentioned by the participants as a major caveat of online feedback.

Although these studies have shed light upon the issue of peer feedback in second language writing classes with regard to the perceptions and attitudes, some of them were not without minor limitations. In some tasks, the number of online tasks were limited (Chang, 2012; Xu, 2007); learners should be given sufficient time to get familiar with the social environment of the online peer feedback to be able to assess its affordances. The small sample size was the limitation of Xu (2007). This caveat can decrease the generalizability power of this study to other contexts. Another limitation belongs to the study by Ho and Savignon (2007); this study was relied completely on the data gathered by a questionnaire that seems not to be enough for an attitudinal study. In addition, some of the studies (Ho \& Savignon, 2007; Xu, 2007) used word processor for giving comments and email service or a website to exchange texts, which led to temporal and logistic burden for learners. Furthermore, in Guardado and Shi's (2007) and Ho and Savignon's (2007) studies, there was no space for learners' interaction over the text and comments that deprived learners from a precious scaffolding tool. The present study aims at not only avoiding these limitations, but also employing an interactive website, which is suitable for both annotation and discussions. In this system, comments and discussions are provided in the same place which can improve the quality of comments and the lengths of discussions.

This study is of significance as it probes into the effect of CMC on EFL learners' attitudes towards and perceptions of written peer feedback in the traditional educational system of Iran; the importance of context in peer feedback is highlighted by Rahimi (2013), Liu and Hansen (2002), and Hyland and Hyland (2006) who believe that since peer feedback is a social action, unique features of factors involved (people, materials, medium, etc.) can affect the dynamics of peer response.

Furthermore, the number of studies on CMC feedback in the domain of second language writing is too limited (AbuSeileek \& Abualsha'r, 2014) and there are many niches in the literature that should be occupied to uncover the unknown aspects of CMC peer feedback.

\section{Methodology}

This study utilized a triangulated method for data collection and it sought to answer the following research questions:

Research question one: Can computer-mediated communication affect EFL learners' attitudes towards and perceptions of written peer feedback?

Research question two: What are EFL learners' perceptions of Computer-mediated peer feedback?

\section{Participants}

Forty-one upper intermediate university students majoring English Language literature participated in the present study. These participants studied in two control $(\mathrm{n}=23)$ and experimental $(\mathrm{n}=18)$ groups. The participants were selected based on availability sampling. However, random assignment was employed to provide different treatments to different classes. As the students of English Language Literature, the participants were required to pass a range of courses related to language skills and components to reach advanced level of English Language proficiency to prepare for the specialized courses pertinent to their major. The present course was one of these classes that was mandatory and was held once a week. The participants were given Oxford Placement Test (Allan, 1985) at the beginning of the study, the results indicated that they were upper-intermediate English language learners, and the participants of both classes were of the same English Language proficiency level (online group= 34.61 , conventional group $=34.13, \mathrm{t}=.40, \mathrm{p}<.05, \mathrm{df}=39$ ). The native language of all students was Persian. The participation in the present research (questionnaire and interview sections) was voluntary, and all of the participants accepted to take part in the study.

\section{Instruments}

In order to find out the students' perceptions and attitudes towards written feedback, a series of questions were taken from Tsui and $\mathrm{Ng}$ (2000) and Chuang (2004) to formulate an attitude and perception questionnaire. The questionnaires used to reveal 


\section{EFL LEARNERS' ATTITUDES AND PERCEPTIONS OF ONLINE AND CONVENTIONAL PEER WRITTEN FEEDBACK: A TERTIARY LEVEL EXPERIENCE}

students' perception of written peer feedback had some subsections including usefulness of reading peers' writings (6 items), usefulness of reading peers' written comments ( 6 items), and the effects of revisions on students' improvement ( 6 items). To check the internal consistency of the measures, Cronbach alpha was employed and the Cronbach's alpha reliability indices found to be .85 and .88 , for the first and second administrations, respectively, which according to Pallant (2007) were acceptable.

Students' attitude towards peer feedback was also measured for further analysis using two questionnaires. The scale that measured students' attitude toward peer feedback consisted of four subsections; students' preference towards peer activity ( 5 items), students' participation in peer review activity (4 items), students' review ability (4 items), and students' motivation toward peer review activity ( 5 items) were four sections of this questionnaire that yielded the Cronbach's alpha reliability of .81 for the first administration and .83 for the second one. These items were provided in the form of a Likert scale having options ranging from "strongly disagree" to "strongly agree".

The medium of providing and receiving feedback in this study in the experimental groups was an interactive website. This website, which is accessible through http://www.annotationtool.com, provides both the teacher and the students facilities to upload drafts with ease, to add comments to the uploaded essays, and upload the revised version with ease. The criteria for giving teacher and peer feedback were classified in 6 categories: ideas/content, organization, sentence fluency, voice, word choice, and conventions, which were set up by the researcher as the default categories on the website.

\section{Data collection procedures}

One week before the initiation of the treatment, the participants answered the questionnaires. During the treatment, which lasted for six weeks, the students in the CMC group employed an interactive website to exchange comments and discuss over them. They uploaded their texts and provided comments on their classmates' paper and discussed the comments in an asynchronous manner. However, the participants of the conventional class wrote the comments on the first draft paper and exchanged the papers in person. In both groups, the students were asked to submit both first and revised versions of their writings. At the end of the treatment, the participants of both groups responded to the questionnaires, and a few of them participated in the interviews.

The results of the questionnaires were analyzed quantitatively; the mean scores of each item and different subcomponents of each questionnaire were computed. A set of t-tests were applied to pinpoint the significant differences between the two groups' perceptions of and attitudes towards written peer feedback. The interviews were analyzed qualitatively. The researcher attempted to find the most significant patterns and relate them to the subcomponents of the questionnaire to have a better understanding of the issue in a triangulated fashion. Major categories were identified and reduced to a manageable number with sufficient data supporting the theme. The researcher analyzed the data twice with an interval of two weeks and the subsequent refinements were done. In addition, a PhD holder of TEFL who is an experienced researcher examined the sentences and themes who found $13(2.06 \%)$ out of 630 sentences of the sentences incompatible with the themes; five of them were omitted, and eight sentences were moved to other categories.

\section{Results and discussion}

The comparison of the results of the pre-treatment questionnaires indicated the homogeneity of the two computer-mediated and conventional groups with regard to their initial state of attitude and perception of peer feedback. The results of independentsamples t-test for comparing these components are presented in Table 1.

Table 1. T-test results for the difference between the mean scores of the answers to the attitude and perception questionnaires

\begin{tabular}{lcccc}
\hline Perception questionnaire & Conventional & Online & $\mathrm{T}$ & sig \\
\hline Usefulness of reading peers' writings & 13.73 & 14.44 & 1.26 & .214 \\
\hline Usefulness of reading peers' written comments & 15.52 & 16.05 & 1.25 & .268 \\
\hline Aspects of their writing improved after the revision & 15.52 & 15.33 & .404 & .689 \\
\hline & & & & \\
\hline Attitude questionnaire & & & & \\
\hline Students' preference towards peer activity & 13.39 & 13.16 & .688 & .496 \\
\hline Students' participation in peer review activity & 10.73 & 10.44 & .467 & .643
\end{tabular}




\section{EFL LEARNERS' ATTITUDES AND PERCEPTIONS OF ONLINE AND CONVENTIONAL PEER WRITTEN FEEDBACK: A TERTIARY LEVEL EXPERIENCE}

\begin{tabular}{lcccc}
\hline Students' review ability & 11.04 & 10.38 & 1.608 & .111 \\
\hline Students' motivation toward peer review activity & 13.08 & 12.55 & 1.02 & .313
\end{tabular}

As evident in Table 1, no significant difference between the perceptions of and attitude toward peer feedback of the two groups was witnessed. Thus, it can be stated that in the initial state and before the initiation of the treatments, the students were similar with regard to their perception of and attitude towards peer feedback.

Research question one: Can computer-mediated communication affect EFL learners' attitudes towards and perceptions of written peer feedback?

\section{Closed-ended questionnaire}

In order to answer this question, two questionnaires, which included closed-ended and open-ended questions and a series of semi-structured interviews were employed. The first part of this section deals with the results of the closed-ended questionnaires. These questionnaires were given to the students in both conventional and online peer feedback groups. Table 2 shows the mean scores of the items pertaining to the perception questionnaire after the treatment. The mean scores of each item and each subcomponent of the questionnaire of the two groups of the conventional and online groups were compared using independent-samples t-tests.

Table 2: T-test results for the difference between the mean scores of the answers to the perception questionnaire

\begin{tabular}{|c|c|c|c|c|}
\hline & $\begin{array}{l}\text { Conventional } \\
\text { peer feedback }\end{array}$ & $\begin{array}{l}\text { Online peer } \\
\text { feedback }\end{array}$ & $\mathrm{T}$ & Sig \\
\hline I liked reading my classmates' compositions. & 2.78 & 3.97 & 5.04 & $.000^{*}$ \\
\hline I found reading my classmates' compositions useful. & 2.73 & 4.21 & 6.15 & $.000^{*}$ \\
\hline $\begin{array}{l}\text { Reading my classmates' compositions gave me more } \\
\text { ideas. }\end{array}$ & 2.65 & 4.00 & 5.44 & $.000^{*}$ \\
\hline $\begin{array}{l}\text { Reading my classmates' compositions helped me to } \\
\text { improve the organization of my composition. }\end{array}$ & 2.39 & 3.57 & 4.511 & $.000^{*}$ \\
\hline $\begin{array}{l}\text { Reading my classmates' compositions helped me to } \\
\text { improve the language (including grammar and } \\
\text { vocabulary) of my composition. }\end{array}$ & 2.91 & 3.52 & 1.88 & .067 \\
\hline I benefited from reading my classmates' compositions. & 3.34 & 3.78 & 2.46 & $.018^{*}$ \\
\hline $\begin{array}{l}\text { I liked the way that my classmates gave me written } \\
\text { comments on my compositions. }\end{array}$ & 3.26 & 3.73 & 2.11 & $.041^{*}$ \\
\hline I found my classmates' written comments useful. & 3.04 & 3.78 & 3.10 & $.004^{*}$ \\
\hline $\begin{array}{l}\text { My classmates' written comments helped me to enrich } \\
\text { the content of my composition. }\end{array}$ & 3.47 & 3.57 & 1.162 & .252 \\
\hline $\begin{array}{l}\text { My classmates' written comments helped me to } \\
\text { improve the organization of my composition. }\end{array}$ & 2.73 & 3.42 & 2.90 & $.006^{*}$ \\
\hline $\begin{array}{l}\text { My classmates' written comments helped me to } \\
\text { improve the language (including grammar and } \\
\text { vocabulary) of my composition. }\end{array}$ & 2.82 & 3.84 & 4.03 & $.000^{*}$ \\
\hline I benefited from my classmates' written comments. & 3.13 & 3.68 & 2.21 & $.033^{*}$ \\
\hline My composition became better after revisions. & 3.26 & 2.66 & 1.95 & .058 \\
\hline $\begin{array}{l}\text { After each revision, the content of my composition } \\
\text { became richer. }\end{array}$ & 2.69 & 2.83 & .522 & .604 \\
\hline $\begin{array}{l}\text { After each revision, the organization of my } \\
\text { composition became better. }\end{array}$ & 2.69 & 3.33 & 2.14 & $.038^{*}$ \\
\hline $\begin{array}{l}\text { After each revision, the language (including grammar } \\
\text { and vocabulary) of my composition improved. }\end{array}$ & 3.08 & 3.22 & .617 & .541 \\
\hline Revisions helped improved my composition. & 3.04 & 3.05 & .049 & .961 \\
\hline $\begin{array}{l}\text { I hope that my English teacher will continue to use this } \\
\text { approach to teach writing next year. }\end{array}$ & 3.13 & 3.33 & .933 & .356 \\
\hline
\end{tabular}




\section{EFL LEARNERS' ATTITUDES AND PERCEPTIONS OF ONLINE AND CONVENTIONAL PEER WRITTEN FEEDBACK: A TERTIARY LEVEL EXPERIENCE}

\begin{tabular}{lllll}
\hline Usefulness of reading peers' writings & 18.52 & 23.38 & 5.85 & $.000^{*}$ \\
\hline Usefulness of reading peers' written comments & 19.26 & 22.55 & 3.62 & $.001^{*}$ \\
\hline Aspects of their writing improved after the revision & 19.17 & 18.44 & 1.00 & .324 \\
\hline
\end{tabular}

Table 2 indicates the mean scores of the answers of the students to the questions pertaining to their perceptions of peer feedback after the treatment. The items tapped three subcomponents, which were the usefulness of reading peers' texts, the usefulness of reading peers' written comments, and the aspects of their writing improved after the revision.

With regard to the students' perception of the usefulness of reading peers' texts, the mean of this subcomponent was 23.38 (out of 30) for the online group, and 18.25 for the conventional group. The result of the comparison of the two indices led to a significant difference $(\mathrm{t}=5.85, \mathrm{p}<.001)$. The usefulness of reading peers' written comments was the second subcategory that was subjected to comparison. The results, indicated in Table 1 , show that the mean score of the online group was 22.55 , and the mean score of the conventional group was 19.26. The result of the independent-samples t-test for the comparison of these mean scores indicated a significant difference $(t=3.62, p<.002)$. Concerning the impact of the comments on the improvement of the revisions, the mean scores of the two groups were computed. The mean for the control group was 19.17 and for the online group was 18.44. Independent-samples t-test was run to compare the mean scores. The result of the comparison showed an insignificant difference between the means of the two groups $(\mathrm{t}=1.00, \mathrm{p}<.05)$.

Table 3: T-test results for the difference between the mean scores of the answers to the attitude questionnaire

\begin{tabular}{|c|c|c|c|c|}
\hline & $\begin{array}{l}\text { Conventional peer } \\
\text { feedback }\end{array}$ & $\begin{array}{l}\text { Online peer } \\
\text { feedback }\end{array}$ & t-test & sig \\
\hline Generally speaking, I like peer review activity. & 3.21 & 4.05 & 3.83 & $.000 *$ \\
\hline I like to read peer's writings. & 2.95 & 3.73 & 2.82 & $.007 *$ \\
\hline I like my peer to appreciate my works. & 2.91 & 3.10 & 1.28 & 208 \\
\hline I like my peer to read my drafts. & 3.78 & 3.68 & .23 & .816 \\
\hline I think peer review is a good activity. & 3.78 & 3.78 & 1.07 & .287 \\
\hline I enjoy participating in peer review activity. & 2.65 & 3.89 & .975 & .336 \\
\hline $\begin{array}{l}\text { I express my opinions clearly during the peer } \\
\text { review activity. }\end{array}$ & 2.82 & 3.82 & 4.04 & $.000^{*}$ \\
\hline I give sufficient suggestions to the writer. & 2.95 & 3.89 & 4.09 & $.000 *$ \\
\hline I enjoy peer review discussions. & 2.69 & 3.78 & 3.45 & $.001 *$ \\
\hline $\begin{array}{l}\text { My peer gives me correct comments during the } \\
\text { peer review activity. }\end{array}$ & 2.91 & 3.52 & 2.95 & $.005^{*}$ \\
\hline I make good judgments about my peer's papers. & 2.39 & 3.52 & 2.94 & $.005 *$ \\
\hline $\begin{array}{l}\text { I think that I can point out the strengths of my } \\
\text { peers' drafts. }\end{array}$ & 2.39 & 3.73 & 4.26 & $.000^{*}$ \\
\hline $\begin{array}{l}\text { I give correct comments to my peer during peer } \\
\text { review activity. }\end{array}$ & 2.60 & 3.78 & 5.41 & $.000^{*}$ \\
\hline $\begin{array}{l}\text { I participate in the peer review activity because } \\
\text { it is a meaningful activity. }\end{array}$ & 2.82 & 4.10 & 8.42 & $.000 *$ \\
\hline $\begin{array}{l}\text { I participate in the peer review activity so that I } \\
\text { can learn from peers. }\end{array}$ & 2.34 & 4.15 & 7.41 & $.000^{*}$ \\
\hline $\begin{array}{l}\text { I participate in the peer review activity because } \\
\text { it improves my writing. }\end{array}$ & 3.17 & 4.10 & 5.39 & $.000^{*}$ \\
\hline $\begin{array}{l}\text { I participate in the peer review activity because I } \\
\text { like it. }\end{array}$ & 3.26 & 3.84 & 5.49 & $.000^{*}$ \\
\hline I use peer comments in revising the drafts. & 2.69 & 4.21 & 4.04 & $.000^{*}$ \\
\hline Students' preference towards peer activity & 16.95 & 18.72 & 3.218 & $.003 *$ \\
\hline Students' participation in peer review activity & 12.21 & 15.61 & 5.814 & $.000^{*}$ \\
\hline Students' review ability & 13.86 & 14.83 & 1.670 & 103 \\
\hline
\end{tabular}




\section{EFL LEARNERS' ATTITUDES AND PERCEPTIONS OF ONLINE AND CONVENTIONAL PEER WRITTEN FEEDBACK: A TERTIARY LEVEL EXPERIENCE}

\begin{tabular}{lllll}
\hline Students' motivation toward peer review activity & 16.47 & 20.77 & 6.310 & $.000^{*}$ \\
\hline
\end{tabular}

As indicated in Table 3, the students in the online group had more positive attitudes in three out of the four comparisons. The mean of the students in the online group for their preference towards peer activity was 18.72 , while it was 16.95 for the conventional group. Running independent-samples $t$-test showed that the means were significantly different $(t=3.218, p<.005)$. Although the students in both conventional and online groups had positive attitude towards participation in the peer review activity (12.21 for the conventional group, and 15.61 for the online group), the result of the t-test showed a significant difference between the means of the two groups $(\mathrm{t}=1.67, \mathrm{p}<.001)$. A similar case was observed for the students' motivation for engaging in peer review activities. The attitude of the students in the online group towards the motivational aspects of peer feedback (20.77) was higher than that of the students in the conventional group (16.47). The mean scores of the two groups were compared by the use of an independent-samples t-test, which resulted in a significant difference $(t=6.31, p<.001)$. The only insignificant difference between the means of the two groups was related to the students review ability $(\mathrm{t}=1.67, \mathrm{p}<.05)$. However, in this subcomponent of the students' attitude towards peer feedback, the participants in the online group had higher mean (14.83) in comparison to their counterparts in the conventional group (13.86).

The note-worthy point of Tables 2 and 3 is that, except for one item (item 4 in the perception questionnaire), the means of the all items were more than 2.5. This shows that the students, in both online and conventional classes, had a positive perception of the peer response activity. The results of independent-samples t-tests indicated that the online peer CMC group students had more positive attitudes towards peer feedback in 5 subcomponents (out of 7). However, with regard to two components which were the improvement of their texts after revision and the students' review ability, the participants of the two groups were not significantly different.

The results concerning the students' perceptions of and attitude towards peer feedback found in this study are in line with the previous studies in both conventional classes (Fujieda, 2007; Rollinson, 2004; Roskams, 1999; Tang \& Tithecott, 1999), and online classes (Ho \& Savignon, 2007; Huynh, 2008; Marefat, 2004; Xu 2007; Yang 2010), which indicated positive perceptions of and attitudes towards peer feedback.

\section{Open-ended questionnaire and interview}

The second sub-part of this section deals with the students' responses to the questions of the open-ended questionnaire and the interview. All of the students in both online and conventional classes answered the questions of the questionnaire, and participated in the interviews. The students' opinions were categorized into a few major categories based on their common themes.

\section{Usefulness of peer review activity}

When asked about the usefulness of the peer review activity, the students, unanimously, admitted the benefits of peer feedback $\left(\mathrm{N}_{\text {total }}=41 / 41\right)$. Almost all of the interviewees talked about the advantages of reading others' texts and getting familiar with their styles of writing $\left(\mathrm{N}_{\text {conventional }}=16 / 23(69.5 \%) \& \mathrm{~N}_{\mathrm{CMC}}=16 / 18(88.8 \%)\right.$ ). They also found comments beneficial since the comments given to them by the students were more understandable than those provided by the teacher $\left(\mathrm{N}_{\text {conventional }}=15 / 23\right.$ $\left.(65.2 \%) \& \mathrm{~N}_{\mathrm{CMC}}=14 / 18(77.7 \%)\right)$. These points support the findings of the closed-ended attitude questionnaire's items 1 to 6 (Usefulness of reading peers' writings) and, 6 to 12 (Usefulness of reading peers' written comments. These findings were in line with those of the closed-ended questionnaire; the participants showed their belief in the usefulness of reading others' texts and reading others' comments.

\section{High level of linguistic self-confidence}

When asked about their ability and feeling of their ability to give critique on their peer's writing, the majority of the students of both groups talked about their linguistic, writing, and commenting abilities $\left(\mathrm{N}_{\text {conventional }}=19 / 23(82.6 \%) \& \mathrm{~N}_{\mathrm{CMC}}=16 / 18\right.$ $(88.8 \%)$ ); they mentioned that peer feedback activity gave them this sweet chance to be positioned as critics. Some of them 


\section{EFL LEARNERS' ATTITUDES AND PERCEPTIONS OF ONLINE AND CONVENTIONAL PEER WRITTEN FEEDBACK: A TERTIARY LEVEL EXPERIENCE}

$\left(\mathrm{N}_{\text {conventional }}=19 / 41(46.3 \%)\right)$ talked about acting as a teacher, and bragged about their position of knowledgeable language users, and not learners. All in all, it can cautiously be inferred that peer feedback activity positively affected the learners' linguistic self-confidence.

\section{High level of participation}

With regard to the participation in the peer feedback activity, the students' eagerness to involve in peer feedback activities supports the findings of the items 6 to 9 of the perception questionnaire. The students found the negotiations and discussions both fruitful and entertaining $\left(\mathrm{N}_{\text {conventional }}=14 / 23(60 \%) \& \mathrm{~N}_{\mathrm{CMC}}=15 / 18(83.3 \%)\right)$. The students were asked if they had ignored their peer's comments for a reason or another. Their answers support the results of the items 10 to 13 of the perception questionnaire. They said they would take a look at the comments, and applied them if they were acceptable. Some $\left(\mathrm{N}_{\mathrm{CMC}}=12 / 18\right.$ $(66.6 \%)$ ) of the CMC group students stated that it was impolite not to read others' ideas, and leave their questions and comments unanswered; however, the participants of the conventional group did not find it impolite to ignore the comments because it was the teacher and not the peer who collected the next draft. The findings also indicated that the resemblance of the online commenting activities with the real-life exchange of ideas and future academic publication process (which had been stated by the teacher) made them take the activity more seriously.

\section{Face-saving function}

More than half of the participants $\left(\mathrm{N}_{\text {total }}=26 / 41(63.4 \%)\right.$ ) of both groups talked about the way the comments provided by their peers helped them solve major problems of their writing that could have been led to a face-losing situation if the teacher found them. The participants found the comments as a preliminary filter protecting their self-esteem. The following quotation is a sample of different statements supporting the face-saving function of peer feedback, "When one of your friends reads your text, she will let you know about the mistakes that could have been traced by the instructor, which is embarrassing. By the use of peer feedback, you can feel more confident when you submit your revised text to the teacher. This is relaxing."

\section{Research question two: What are EFL learners' perceptions of Computer-mediated peer feedback?}

\section{Time-independency}

All of the students believed that time-independency was a dominant feature in online feedback. They believed that they found it very practical since they could discuss their problems, ideas, etc. with their friends whenever they wanted or needed. For instance, they could connect to each other late at night or even early in the morning. Many of the students said that they found it even more advantageous because they were not limited to university rules or class hours. The majority of the students (15/ $18(83.3 \%)$ ), also, stated that since they were not forced to provide responses for the comments on the spot, they could reflect upon the issue and give an appropriate thoughtful response. As Chang (2009) argues, the asynchronicity can help the learners follow the activity at their own pace and provide more accurate comments.

\section{Place-independency}

The second feature mentioned by the majority of students $(14 / 18(77.7 \%)$ was the place-independent nature of the online peer feedback activity. Almost all students said that it provided a sense of freedom. Moreover, the access to internet is a commonplace issue. One of the participants stated, "Unlike conventional classes, you are not forced to be in a specific place to discuss over the texts. The use of internet gives you a sort of freedom to decide on the time of exchanging comments". The participants exemplified different ways to connect to the internet such as PCs at home, cell phone connections, public wireless connections and asserted they could access the texts and comments, no matter whether they were on vacation, at home or in the dormitory. One of the students said, "The best point about this course was that I was able to do my assignments when I was on my way to my dormitory. I have to take a shuttle bus to get to the dormitory; I took advantage of this time by connecting to the internet with my tablet, and signed into the website to check the discussions over the comments".

\section{Online resources}

Many students (11/18 (61.1\%) stated that they used search engines while writing. They believed that online resources have helped them in various ways such as providing better diction for the students, solving their problems with grammatical 


\section{EFL LEARNERS' ATTITUDES AND PERCEPTIONS OF ONLINE AND CONVENTIONAL PEER WRITTEN FEEDBACK: A TERTIARY LEVEL EXPERIENCE}

structures and coming up with the newest ideas related to the topic. All in all, it seems that the students were equipped with sufficient abilities to use the online resources efficiently to write their texts and comment on others' texts.

\section{Negotiation over the given comments and sense of audience}

Another point welcomed by the students was the negotiations over the given comments. They believed that this sort of communication helped them make sure about the accuracy of the comments. Some of them (14/18 (77.7\%)) stated that they could improve the content of their texts by a series of questions and answers exchanged between the writer and the critic. A few students (4/18 (22.2\%) firmly stated that when the comment-giver was not accessible to make himself clear, the majority of comments were incomprehensible and would be overlooked by the comment-receiver. The negotiations gave the students a feeling that someone real was reading the text and discussed over the content and the language in a real-life manner; this is a feature of peer feedback activity (Kamhi-Stein, 2000), which is facilitated by the computer-mediated communication. One of the students made an analogy between uploading an assignment and publishing a text in a billboard. She indicated that in both conditions a group of people could read your text and get familiar with your ideas, so it was logical to pay attention to the content of the text to avoid being belittled by a stated idea.

\section{Far from the excitement extremes}

The interviews revealed that the online peer review activity was successful in arousing the participants' excitement, inquisitiveness, and perseverance, but it was not affectively troublesome. The respondents found the activity as an educational game in which they had to succeed, so while they were striving for the triumph, which was defined as giving sound comments and writing immaculately; however, they were not overwhelmed with the atmosphere. As one of the students said, "You know, in games, sometimes you are beaten, but you can lose like a champion by doing your best".

\section{Online, face-to-face, or a combination?}

The last finding of the present study has to do with the students' desired type of peer feedback. None of the students disliked the online type of comment exchange. More than 70 percent of the students (13/18) found the online reciprocal medium for peer feedback activities sufficient. However, around 30 percent of the participants (5/18) stated that a combination of both online and face-to-face feedback activities were necessary to be fully beneficial.

\section{Discussion}

The results of the present study indicated the EFL learners' positive attitudes towards and perceptions of peer feedback in the writing class in the tertiary level. The results of the present study revealed that the online group participants were more content with the peer feedback activity. In addition to the benefits of the computer-mediated peer feedback, discussed in the introduction section and are compatible with the findings of the present study, the features of online peer feedback activities can be reviewed in the light of general education theories.

One of the education theories that has gained momentum in general education in recent years is Andragogy, which is contrasted with pedagogy, and has to do with the art and science of teaching adults (Knowles, 1980). To Knowles, adult learners are of different characteristics from children which lead to differences in their process of learning, so different types of education are required for them to have an efficient educational system (Ganqa, 2012). Knowles (1984) argue that the aim of a successful adult education program is to establish mutual respect, collaborativeness, supportiveness, openness, and fun. When we juxtapose the findings of the interview and the principles of Andragogy, we can trace some meaningful connections.

One of the principles of Andragogy is the adult learners' autonomy and self-directedness. Adult learners require freedom to direct themselves in the process of learning. Teachers of adult courses should engage learners in activities and let them experience the activity in their preferred manner. The role of the teacher is to facilitate and guide learners to reach their own goals. The online peer feedback activity gives students the opportunity to take charge of their own learning processes in their preferred manner. The temporal and spatial independency in the CMC peer feedback enabled the learners to move at their own pace, which can reduce the anxiety and increase the linguistic self-confidence of the learners (Tuzi, 2004; Ware \& Warschauer, 2006). Another pertinent principle of Andragogy is that adults work assiduously when they find the learning activity related to their work, future career or interest. The students reported the relevance of the online commenting process to their future 


\section{EFL LEARNERS' ATTITUDES AND PERCEPTIONS OF ONLINE AND CONVENTIONAL PEER WRITTEN FEEDBACK: A TERTIARY LEVEL EXPERIENCE}

academic career activities as a reason for working earnestly. The last relevant Andragogy principle is reported to be the adults' need to be respected. Adult learners require to be communicated in a respectful manner. They should be behaved in a way to feel that their capabilities are honored. The delegation of the teacher's judging and commenting position to the leaners of the peer feedback activity can be another reason for the participants' positive attitude towards peer feedback.

The central role of the medium in the sociocultural theory and its effects on the condition of learning is well-established in the literature (Lantolf, 2000). In the present study, the students were involved in using a website to exchange comments. This medium facilitated the participants' sharing their peers their linguistic and cognitive resources. The findings indicated that online peer feedback activity can be beneficial at different levels. At the educational level, the participants "pool their resources" (Bruffee, 1984, 644) to do the tasks more easily; in other words, sharing the information is just some clicks away (Liu \& Hansen, 2002; Zheng, 2012). At the psychological level, online asynchronous peer feedback is of its own stress-free atmosphere, which facilitate the exchange of comments and consequently the extension of learners' interlanguage (RouxRodriguez, 2003; Ware \& Warschauer, 2006). At the philosophical and political level, the facilitation of the distribution of knowledge among different interactants of a community of practice is facilitated by the employment of the online media in educational activities (Chapelle, 2003; Corneli \& Danoff, 2011; White, 2003).

\section{Conclusion}

The findings of this study revealed that EFL students at the tertiary level found both conventional and CMC peer feedback beneficial. However, in comparison to their conventional group counterparts, the CMC group students had more positive perceptions of and attitudes towards peer feedback in 5 out of 7 subcategories. The participants found peer review activity valuable and beneficial, but what is worth-noticing is the higher level of the CMC group; it seems that the experience of the $\mathrm{CMC}$ group students of peer feedback activity was more pleasant. The anxiety-free communications due to the asynchronous nature of the $\mathrm{CMC}$ communication, the absence of spatial and temporal inconveniences, the use of online resources due to the employment of the internet while exchanging comments, the negotiation of meaning, and real-life exchange of comments in the CMC condition, which was similar to their daily chats in the cyberspace were the benefits of CMC written peer feedback over the conventional written peer feedback found in the present study.

The findings of this study implies that the medium of peer feedback exchange can lead to diverse perceptions of and attitudes towards peer feedback. Facilitative or debilitative perceptions and attitudes can emerge and affect the effectiveness of instructional scaffolds (peer feedback in the present case). The post-treatment questionnaire administration indicated noticeable differences in the participants' perceptions of and attitudes towards peer feedback of the conventional and computer-mediated groups. It can be inferred from these findings that not only peer feedback but also the medium used to convey it function as mediators, can lead to learners' different affective experiences. As the literature of second language writing domain mirrors, in the majority of studies (e.g., Burston, 2001; Huynh, 2008; Song \& Usaha, 2009; Yeh \& Lo, 2009) computer-mediated feedback was found superior over the conventional counterpart with regard to the ultimate outcome, i.e., writing ability improvement; one of the reasons, among other variables, that can be attributed to this result is learners' perceptions.

With regard to pedagogical implications of this study, the results encourage second language teachers to employ peer feedback activity in their writing classes. Whenever feasible, teachers can resort to different online media to benefit from the affordances of new technologies to let students have more positive perceptions of and attitudes towards their learning activities, which can revamp learners' second language learning experience (Soleimani \& Hanafi, 2013). To select the right medium for the exchange of peer comments among different CMC devices which are at teacher's disposal, one should take the students' technological facilities, social condition, language ability, computer literacy, etc. into consideration to benefit the best from the activity.

Two limitations can be mentioned for the present study. The first limitation has to do with the sampling procedure, which was not random; this calls for the cautious employment of the results, and further research by other researchers. Furthermore, this study benefited from questionnaires and interviews to collect data. Further studies can employ stimulated recall interviews to move from the observation (data) to the students' perceptions. Case study and close analysis of a few participants for several peer feedback sessions in online and conventional conditions can reveal the affordances of CMC and conventional peer feedback activities. Micro- and macro-ethnographies can also be used to uncover the cultural specifications that affect second language learners' perceptions of and attitudes towards peer feedback activities.

\section{References}




\section{EFL LEARNERS' ATTITUDES AND PERCEPTIONS OF ONLINE AND CONVENTIONAL PEER WRITTEN FEEDBACK: A TERTIARY LEVEL EXPERIENCE}

AbuSeileek, A., \& Abualsha'r, A. (2014) Using peer computer-mediated corrective feedback to support EFL learners' writing. Language Learning \& Technology, 18(1), 76-95.

Ary, D., Jacobs, C. L., \& Sorensen, C. (2010). Introduction to Research in Education. Belmont, CA: Wadsworth, Cengage Learning.

Belcher, D. (1999). Authentic interaction in a virtual classroom: Leveling the playing field in a graduate seminar. Computer and Composition, 16, 253-267.

Belz, J., \& Kinginger, C. (2003). Discourse options and the development of pragmatic competence by classroom learners of German: The case of address forms. Language Learning, 53(4), 591-647.

Breuch, L. (2004). Virtual peer review. Albany, NY: SUNY Press.

Bruffee, K. (1984). Peer tutoring and the 'conversation of mankind.' In G. Olson (Ed.), Writing Centers: Theory and administration (pp. 3-15). Urbana, IL: National Council of Teachers of English.

Bruner, J. S. (1978). The role of dialogue in language acquisition. In A. Sinclair, R. Jarvella \& W. J. M. Levelt (Eds.), The Child's Conception of Language. (pp. 241-256). New York: Springer-Verlag.

Chang, C. F. (2009). Peer review through synchronous and asynchronous CMC modes: A case study in a Taiwanese college English writing course. The JALTCALL Journal, 5(1), 45-64.

Chapelle, C. A. (2003). English Language Learning and Technology. Dordrecht: John Benjamins.

Chuang, H. C. (2004). Taiwanese students' perceptions on peer review activity. Unpublished MA thesis. Ming Cuang University.

Colomb, G. C., \& Simutis, J. A. (1996). Visible conversation and academic inquiry: CMC in a culturally diverse classroom. In S. Herring (Ed.), Computer-mediated communication: Linguistic, social and cross-cultural perspectives (pp. 203222). Amsterdam/Philadelphia: John Benjamins.

Cooper, M. M., \& Selfe, C. L. (1990). Computer conferences and learning: Authority, resistance, and internally persuasive discourse. College English, 52, 847-869.

Corneli, J., \& Danoff, C. J. (2011). Paragogy: Synergizing individual and organizational learning. In the 1st International Conference on Learning Analytics and Knowledge.

DiGiovanni, E. \& Nagaswami, G. (2001). Online peer review: an alternative to face-to-face? ELT Journal, 55: $263-72$.

Dippold, D. (2009). Peer feedback through blogs: Student and teacher perceptions in an advanced German class. Recall, 21(1): 21-36.

Englert, C. S., Wu, X., \& Zhao, Y. (2005). Cognitive tools for writing: Scaffolding the performance of students through technology. Learning Disabilities Research and Practice, 20 (3), 184-198.

Fujieda, Y. (2007). Perceptional change toward peer response: How writers incorporated feedback into revisions. KyoaiGakuen Journal, 7, 139-153.

Ganqa, N. H. (2012). Research supervision experiences of masters in education students at a South African University. Unpublished Phd dissertation. University of Fort Hare.

Guardado, M. \& Shi, L. (2007). ESL students' experiences of online peer feedback. Computers and Composition, 24, 443461.

Hiltz, S. R. \& Turoff, M. (1978). The network nation. Cambridge, MA: MIT Press. 


\section{EFL LEARNERS' ATTITUDES AND PERCEPTIONS OF ONLINE AND CONVENTIONAL PEER WRITTEN FEEDBACK: A TERTIARY LEVEL EXPERIENCE}

Ho, M.C., \& Savignon, S. J. (2007). Face-to-face and Computer-mediated Peer Review in EFL Writing. CALICO Journal, 24(2), 269-290.

Huynh, M. H. (2008). The impact of online peer feedback on EFL learners' motivation in writing and writing performance: a case study at Can Tho University. Unpublished MA thesis at Can Tho University, Vietnam.

Hyland, K. (2003). Second Language Writing. New York: Cambridge University.

Jacobs, G. M. \& McCafferty, S. G. (2006). Connections between cooperative learning and second language learning and teaching. In: S. G. McCafferty, G. M. Jacobs \& A. C. DaSilvaIddings (Eds.), Cooperative Learning and Second Language Teaching. Cambridge: Cambridge University Press.

Kamhi-Stein, L. D. (2000). Looking to the future of TESOL teacher education: Web-based bulletin board discussions in a methods course. TESOL Quarterly, 34, 423-455.

Kern, R. G. (1995). Restructuring classroom interaction with network computers: Effects on quantity and characteristics of language production. The Modern Language Journal, 79, 457-476.

Knowles, M. S. (1980). The modern practice of adult education: From pedagogy to andragogy. Chicago: Follett.

Knowles, M. S. (1984). Andragogy in action. San Francisco: Jossey-Bass.

Lantolf, J. P. (2000). Sociocultural theory and second language learning. Oxford, UK: Oxford University Press.

Lantolf, J. P., \& Poehner, M. E. (Eds.). (2008). Sociocultural theory and the teaching of second languages. London: Equinox.

Liu, J., \& Hansen, J.G. (2002). Peer response in second language writing classrooms. Ann Arbor, MI: The University of Michigan Press.

Marefat, F. (2004). Using Email to increase student feedback in an EFL writing class. Journal of Social Sciences and Humanities of Shiraz University, 21 (1), 126- 133.

Pallant, J. (2007). SPSS survival manual: A step by step guide to data analysis using SPSS for Windows. Maidenhead: Open University Press.

Palmquist, M. E. (1993). Network-supported interaction in two writing classrooms. Computers and Composition, 9(4), 25-57.

Pellettieri, J. (2000). Negotiation in cyberspace: The role of chatting in the development of grammatical competence. In M. Warschauer \& R. Kern (Eds.), Network-based language teaching: Concepts and practice (pp. 59-86). Cambridge: Cambridge University Press.

Rahimi, M. (2013). Is training peer reviewers worth its while? The effect of training peer reviewers on the quality of their feedback and writing. Language Teaching Research, 17 (1), 67-89.

Rahimi, M., \& Mehrpour, S. (2009). A complete guide to academic writing for EFL learners: Writing paragraphs and essays. Shiraz, Iran: Shiraz University Press.

Rollinson, P. (2004). Experiences and perceptions in an ESL academic writing peer response group. Estudios Ingleses de la Universidad Complutense, 12, 79-108.

Roskams, T. (1999). Chinese EFL students' attitudes to peer feedback and peer assessment in an extended pairwork setting. RELC Journal, 30 (1), 79-123.

Roux-Rodriguez, R. (2003). Computer-mediated peer response and its impact on revision in the college Spanish classroom: A case study. Unpublished doctoral dissertation, University of South Florida, USA. 


\section{EFL LEARNERS' ATTITUDES AND PERCEPTIONS OF ONLINE AND CONVENTIONAL PEER WRITTEN FEEDBACK: A TERTIARY LEVEL EXPERIENCE}

Shang, H. F. (2007). An exploratory study of e-mail application on FL writing performance. Computer Assisted Language Learning, 20(1), 79-96.

Soleimani, H., \& Hanafi, S. (2013). Iranian Medical Students' Attitudes towards English Language Learning. International Research Journal of Applied and Basic Sciences, 4 (12), 3816-3823.

Spitzer, M. (1990). Local and global networking: Implications for the future. In D. Holdstein \& C. Selfe (Eds.), Computers and writing: Theory, research, practice (186- 207). New York, NY: MLA.

Tang, G. M., \& Tithecott, J. (1999). Peer response in ESL writing. TESL Canada Journal, 6(2), 20-38.

Tsui, A.B.M., \& Ng, M. (2000). Do secondary L2 writers benefit from peer comments? Journal of Second Language Writing, $9(2), 147-170$

Tuzi, F. (2004). The impact of e-feedback on the revisions of L2 writers in an academic writing course. Computers and Composition, 21, 217-235.

Villamil, O. S., \& Guerrero, M. C. M. de. (1996). Peer revision in the L2 classroom: Social-cognitive activities, mediating strategies, and aspects of social behavior. Journal of Second Language Writing, 5(1), 51-75.

Vygotsky, L. S. (1978). Mind and Society. Cambridge, MA: Harvard University Press.

Ware, D. \& Warschauer, M. (2006) Electronic feedback and second language writing. In K. Hyland \& F. Hyland (Eds.) Feedback in second language writing: Context and issues (pp. 105-122). London: Cambridge University Press.

Ware, P. D. (2004). Confidence and competition online: ESL student perspectives on web-based discussions in the classroom. Computers and Composition, 21 (4), 451468.

Warschauer, M. (1996). Comparing face-to-face and electronic communication in the second language classroom. CALICO Journal, 13, 7-25.

White, C. (2003). Language learning in distance education. New York: Cambridge University Press.

$\mathrm{Wu}, \mathrm{W}$. (2006). The effect of blog peer review and teacher feedback on the revisions of ESL writers. Journal of Education and Foreign Languages and Literature 3, 125-139.

Xu, Y., (2007). Re-examining the effects and affects of electronic peer reviews in a first-year composition class. The Reading Matrix, 7(2), 1-21.

Yang, Y. F. (2010). Students' reflection on online self-correction and peer review to improve writing. Computers \& Education, 55. 1202-1210.

\section{Contact details of authors}

Mohammad Hamed Hoomanfard,

$\mathrm{PhD}$ candidate in TEFL,

Payame Noor University,

Tehran, Iran

Email: hamedhooman@gmail.com 


\section{EFL LEARNERS' ATTITUDES AND PERCEPTIONS OF ONLINE AND CONVENTIONAL PEER WRITTEN FEEDBACK: A TERTIARY LEVEL EXPERIENCE}

\section{Biodata}

Mohammad Hamed Hoomanfard is a Ph. D. candidate in Teaching English as a Foreign Language at Payame Noor University, Tehran, Iran. His main research interests include second language writing, second language reading, computerassisted language learning, and learning strategies. He has published several papers in peer-reviewed journals. 